\title{
Optimization of Slow Pyrolysis of Bamboo for Biochar Production using Taguchi's L9 Orthogonal Array
}

\author{
MNZ Moni ${ }^{1}$, Suzana Yusuf $^{* 1}$, ASA Manaf ${ }^{1}$ and Waqiuddin Rahman ${ }^{1}$ \\ ${ }^{1}$ Biomass Processing Laboratory, HICoE Centre for Biofuel and Biochemical Research, Universiti Teknologi PETRONAS, 32610 Bandar \\ Seri Iskandar, Perak, Malaysia.
}

\begin{abstract}
This paper investigates the effects of three parameters (reaction temperature, feedstock particle size and nitrogen flow rate) towards the solid (char) yield from the pyrolysis of bamboo. Three-factor, threelevel Taguchi's L9 Orthogonal Array was used as the experimental design. The char yield at reaction temperatures of $300-500^{\circ} \mathrm{C}$, feedstock particle size of $100-1000 \mu \mathrm{m}$, and nitrogen flow rate of 100 $300 \mathrm{ml} \mathrm{min}{ }^{-1}$ were investigated. The maximum solid yield was predicted based on signal-to-noise $(\mathrm{S} / \mathrm{N})$ ratio and was found to be at $300^{\circ} \mathrm{C}$ reaction temperature, $1000 \mu \mathrm{m}$ feedstock particle size and $100 \mathrm{ml} \mathrm{min}{ }^{-1}$ of nitrogen flow rate. Confirmation runs were conducted to validate the prediction at corresponding predicted conditions.
\end{abstract}

\section{Introduction}

Pyrolysis is a thermal conversion process of carbonaceous materials at elevated temperatures in the absence of oxygen. Pyrolysis products are in the form of solid (char), liquid (tar \& bio-oil) and non-condensable gases (producer gas) [1,2]. Virtually most pyrolysis products can be utilized as fuel for heat and power and also as raw materials for chemical syntheses, thus making the process very attractive [3]. Historically, coal has been the main feedstock for pyrolysis until the greater awareness on the damaging effects of fossil fuels and the emergence of green, renewable and sustainable technology in the past decades have shifted the attentions towards biomass as a promising feedstock for its availability, diversity and inexpensiveness. In recent years, biomass pyrolysis has gained worldwide interests for its versatility, renewability and sustainability features [3-5].

Biochar is the solid product of pyrolysis and can be utilized in various applications ranging from heat and power generation to soil amendment [6-8]. Biochar is also the precursor to activated carbon, which has gained demands for its exceptional adsorption capability as filter materials [9]. Compared to the liquid and gaseous products, biochar requires the least pretreatment prior to use. The quantity and quality of biochar highly depend on the feedstock properties and the pyrolysis conditions. Slow pyrolysis process with long residence time and slow heating rate is commonly used to produce biochar at a maximized fraction, in the expense of liquid and gaseous products $[9,10]$. About $30 \%$ of biochar can be produced by this method, with up to $95 \%$ carbon purity $[9,11]$.

This study investigated the effects of reaction temperature, feedstock particle size and nitrogen flow rate on the pyrolysis of bamboo with emphasis on the biochar yield. The experimental runs were designed using Taguchi's L9 Orthogonal Array method, and the optimum reaction condition that produces maximum solid yield was predicted and compared with the experimental findings.

\section{Materials and methods}

\subsection{Materials}

About $1 \mathrm{~kg}$ of bamboo was obtained from MASSGREEN Resources (M) Sdn. Bhd. in a dried, crushed form with apparent particle size between 1 to $20 \mathrm{~mm}$. The sample was dried at $105 \pm 0.1^{\circ} \mathrm{C}$ for $24 \mathrm{~h}$ in a convection drying oven (UN55, Memmert GmbH, Germany) for complete moisture removal. The moisture content of the sample was determined to be 5.77 wt.\%. The dried sample was ground using a multi mill grinder (PULVERISETTE 25/19, Fritsch GmbH, Germany) and then sieved using an analytical sieve shaker (BA300N, CISA, Spain) to obtain separate samples with a particle size of 100,500 and $1000 \mu \mathrm{m}$. Each sample was stored separately in airtight containers for conservation purpose prior to experiment. 


\subsection{Equipment}

Slow pyrolysis of bamboo was conducted in a laboratory scale autoclave reactor as shown in Fig. 1. Approximately $20 \mathrm{~g}$ of bamboo was measured using a precision scale (FX1200i, A\&D Company Ltd., Japan) and used in each run. The sample was placed in the reactor and manually locked shut. Temperature and nitrogen flow rate were controlled using a PID controller with user input. Air was flushed from the reactor interior by flowing nitrogen into the reactor space at a rate of $300 \mathrm{ml} / \mathrm{min}$ for 4 minutes. The nitrogen flow rate was then set to the desired experimental value $(100,200$ and $300 \mathrm{ml} / \mathrm{min})$. The bamboo sample was heated from room temperature to target temperature $\left(300,400\right.$ and $\left.500^{\circ} \mathrm{C}\right)$ at an average heating rate of $4^{\circ} \mathrm{C} / \mathrm{min}$ and then held for 15 minutes. The reactor allowed to cool down to room temperature in a maintained inert environment before pyrolysis products were collected. The pyrolysis liquid product (condensates + bio oil) was collected in the condensate collector and the solid product was collected from the reactor. Both products were weighed using a precision scale to determine their yield. Gaseous product from pyrolysis was released to open air and the yield of non-condensing gases was determined by difference.

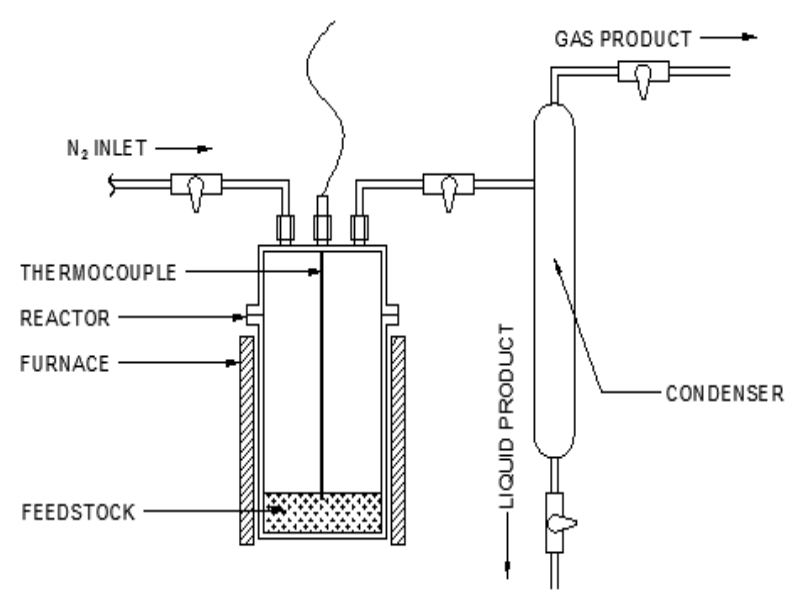

Fig. 1. Autoclave pyrolysis reactor.

\subsection{Experimental procedure and plan}

Experimental runs with three parameters were designed using Taguchi's L9 Orthogonal Array Method in statistical software Minitab 17. Three parameters of interest were studied: feedstock particle size, reaction temperature and nitrogen flow rate; each factor was tested at three levels as shown in Table 1. Nine significant experimental runs were determined by the software instead of 27 runs ( 3 reaction parameters at 3 levels each, $3^{3}=27$ ). The details of the significant nine runs are summarized in Table 2. Based on the obtained product yield data, statistical analyses that include regression model, analysis of variance and signal-to-noise $(\mathrm{S} / \mathrm{N})$ ratio were conducted using the software. The optimum pyrolysis parameter settings to maximize solid product yield was determined using $\mathrm{S} / \mathrm{N}$ ratio with higher-the- better criteria and using Minitab 17 response optimizer feature.

Table 1. Reaction parameters and their levels.

\begin{tabular}{|c|c|c|c|}
\hline Reaction parameters & Level 1 & Level 2 & Level 3 \\
\hline $\begin{array}{c}\text { Factor A: Reaction } \\
\text { temperature } /{ }^{\circ} \mathrm{C}\end{array}$ & 300 & 400 & 500 \\
\hline $\begin{array}{c}\text { Factor B: Feedstock } \\
\text { particle size/ } \mu \mathrm{m}\end{array}$ & 100 & 500 & 1000 \\
\hline $\begin{array}{c}\text { Factor C: Nitrogen } \\
\text { flow rate/ml } \text { min }^{-1}\end{array}$ & 100 & 200 & 300 \\
\hline
\end{tabular}

Table 2. Experimental runs and corresponding parameters determined from Taguchi's L9 Orthogonal Array.

\begin{tabular}{|c|c|c|c|}
\hline Run & $\begin{array}{c}\text { Factor A: } \\
\text { Reaction } \\
\text { temperature } \\
\text { C }\end{array}$ & $\begin{array}{c}\text { Factor B: } \\
\text { Feedstock } \\
\text { particle size/ } \\
\mu \mathrm{m}\end{array}$ & $\begin{array}{c}\text { Factor C: } \\
\text { nitrogen } \\
\text { flow rate/ } \\
\mathrm{ml} \mathrm{min}^{-1}\end{array}$ \\
\hline 1 & 300 & 100 & 100 \\
\hline 2 & 300 & 500 & 300 \\
\hline 3 & 300 & 1000 & 500 \\
\hline 4 & 400 & 100 & 300 \\
\hline 5 & 400 & 500 & 500 \\
\hline 6 & 400 & 1000 & 100 \\
\hline 7 & 500 & 100 & 500 \\
\hline 8 & 500 & 500 & 100 \\
\hline 9 & 500 & 1000 & 300 \\
\hline
\end{tabular}

\section{Results and discussions}

\subsection{Experimental results and statistical analyses}

Table 3 shows the pyrolysis product yields from the significant nine runs. Table 4 shows the response table for $\mathrm{S} / \mathrm{N}$ ratio for all parameters and levels for solid product. The $\mathrm{S} / \mathrm{N}$ ratio range (delta, $\Delta$ ) from Table 4 is the highest in reaction temperature, followed by feedstock particle size and nitrogen flow rate. A larger delta means a larger impact on solid yield due to change in factor, thus indicating that the reaction temperature has the highest influence on solid yield. The factor with the highest influence towards solid production is ranked as 1 (reaction temperature), while the lowest is ranked as 3 (nitrogen flow rate).

Table 5 shows the results for regression analysis and analysis of variance for all product yields. The evaluation of each model was conducted using P-value, where a value of less than 0.05 indicates factors with significant effects towards solid yield. The fit regression model analysis shows that reaction temperature and feedstock particle size have significant roles in determining solid yield in pyrolysis, whereby nitrogen flow rate is found to be insignificant. The $\mathrm{R}^{2}$ and the adjusted $\mathrm{R}^{2}$ of the regression model shows values of above $95 \%$, indicating that the mode equation is statistically reliable to be used 
to predict the solid yield for the untested factor combination.

Table 3. Experimental product yields from pyrolysis reactor.

\begin{tabular}{|c|c|c|c|}
\hline Run & $\begin{array}{c}\text { Solid } \\
\text { yield/wt.\% }\end{array}$ & $\begin{array}{c}\text { Liquid } \\
\text { yield/wt.\% }\end{array}$ & $\begin{array}{c}\text { Gas } \\
\text { yield/wt.\% } \\
\text { (by diff.) }\end{array}$ \\
\hline 1 & 49.34 & 20.88 & 29.78 \\
\hline 2 & 51.16 & 17.40 & 31.44 \\
\hline 3 & 53.33 & 14.66 & 32.01 \\
\hline 4 & 43.95 & 22.56 & 33.49 \\
\hline 5 & 46.14 & 21.63 & 32.23 \\
\hline 6 & 48.77 & 18.89 & 32.34 \\
\hline 7 & 39.27 & 27.27 & 33.46 \\
\hline 8 & 40.44 & 25.61 & 33.95 \\
\hline 9 & 42.69 & 23.34 & 33.97 \\
\hline
\end{tabular}

Table 4. Response table for signal-to-noise $(\mathrm{S} / \mathrm{N})$ ratio for all parameters and levels for solid yield.

\begin{tabular}{|c|c|c|c|}
\hline Level & $\begin{array}{c}\text { Factor A: } \\
\text { Reaction } \\
\text { temperature/ } \\
{ }^{\circ} \mathrm{C}\end{array}$ & $\begin{array}{c}\text { Factor B: } \\
\text { Feedstock } \\
\text { particle } \\
\text { size/ } \mu \mathrm{m}\end{array}$ & $\begin{array}{c}\text { Factor C: } \\
\text { nitrogen } \\
\text { flow rate/ } \\
\mathrm{ml} \mathrm{min}^{-1}\end{array}$ \\
\hline 1 & 34.19 & 32.87 & 33.25 \\
\hline 2 & 33.30 & 33.20 & 33.21 \\
\hline 3 & 32.21 & 33.64 & 33.23 \\
\hline Delta $(\Delta)$ & 1.99 & 0.77 & 0.04 \\
\hline Rank & 1 & 2 & 3 \\
\hline
\end{tabular}

Table 5. Summary of fit regression and ANOVA results for solid yields.

\begin{tabular}{|l|c|}
\hline \multicolumn{1}{|c|}{ Model } & Value \\
\hline P-value & \\
Regression & 0.000 \\
Factor A: Reaction temperature $/{ }^{\circ} \mathrm{C}$ & 0.000 \\
Factor B: Feedstock particle size/ $\mu \mathrm{m}$ & 0.000 \\
Factor C: nitrogen flow rate $/ \mathrm{ml} \mathrm{min}^{-1}$ & 0.839 \\
\hline Model R $/ \%$ & 99.64 \\
\hline Model R $\mathrm{R}^{2}$ adj./\% & 99.43 \\
\hline Coded equation & \\
$\quad=64.604-0.05238 \mathrm{~A}+0.004538 \mathrm{~B}+0.000161 \mathrm{C}$ \\
\hline
\end{tabular}

Fig. 2 shows the interaction plot of reaction temperature and feedstock particle size and its effects on solid yield. Evidentially, the reaction temperature significantly affects the solid yield, followed next by the particle size. The highest solid yield is produced at $300^{\circ} \mathrm{C}$ and lowest at $500^{\circ} \mathrm{C}$ for all particle sizes with 24.9 to $26.5 \%$ in difference. The effect of particle size on solid yield is determined to be much lower than that of reaction temperature with 7.5 to $9.9 \%$ of difference in all reaction temperature settings. These observations are synonymous with the rank of importance of test factor determined by the Taguchi's Method analysis as shown in Table 4, thus confirming the influences of reaction temperature and particle size on solid yield.

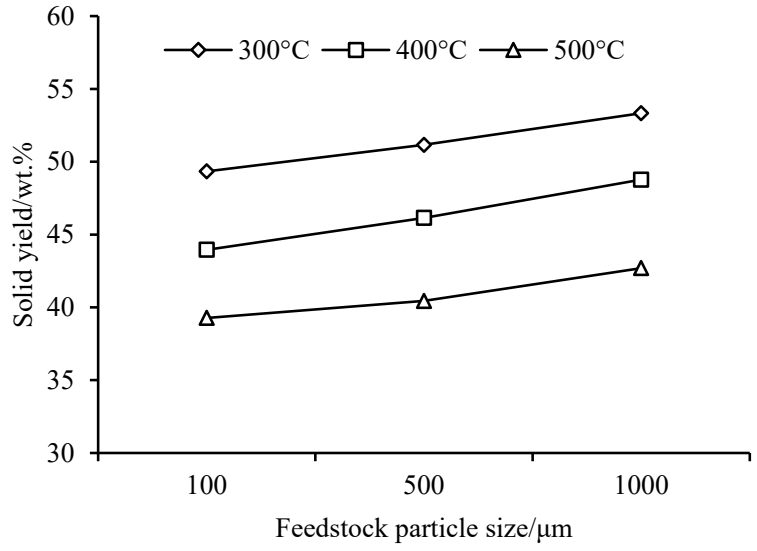

Fig. 2. Interaction plot of reaction temperature and particle size on pyrolysis solid yield.

\subsubsection{Effects of reaction temperature}

Fig. 2 (a) shows the main effect plot for reaction temperature against solid yield based on data means, where a falling trend can be observed. As temperature increases, more volatiles are liberated from the feedstock and undergo secondary reactions into liquid and vapor, resulting to a greater loss in solid mass. This observation is typical to slow pyrolysis and has been discussed in length in literature $[9,12]$. The change in solid yield with temperatures was also found to be comparable with other works on bamboo pyrolysis $[13,14]$. In their study, Chen, Zhou and Zhang [15] discovered that the heating rate of 5 to $30^{\circ} \mathrm{C} \mathrm{min}-1$ has the most important effects to the solid yield from bamboo pyrolysis, where maximum solid yield is produced within this region. In this study, a heating rate of $4^{\circ} \mathrm{C}$ min $^{-1}$ was incorporated, which is advantageous to maximize solid yield.

\subsubsection{Effects of feedstock particle size}

In general, the solid yield from slow pyrolysis increases with feedstock particle size. This is due to the mass transfer resistance within the solid that causes volatiles in larger particles to undergo inter-particle reactions to form char before reaching the particle surface. In contrast, least resistance is experienced in smaller particle size, leading to a higher release of volatiles and the formation of liquid and gaseous products with increasing temperatures [16, 17]. In this study, the solid yield trend with increasing particle size was found consistent with literatures.

\subsubsection{Effects of nitrogen flow rate}

The nitrogen flow rate seems to have insignificant effect to the solid yield as shown in Fig. 2 (c). The residence time for nitrogen in this study is 600,200 and $120 \mathrm{~s}$ at nitrogen flow rate of 100,300 and $500 \mathrm{ml} \mathrm{min}^{-1}$ respectively. Other than to preserve an inert environment for pyrolysis to take place, the role of sweeping gas is to remove pyrolysis vapor from the reactor, where the effects are more prominent on liquid and gaseous pyrolysis products [18]. Only $1 \%$ of variation in solid 
yield was observed when nitrogen flow rate was altered. Despite the minute difference, pyrolysis in completely inert condition produces higher solid yield compared to that in oxygen-deficient environment, as demonstrated by Luo et al. in their study [19], due to no mass loss to partial and complete combustion processes, thus highlighting the important role of nitrogen in maximizing solid yield.

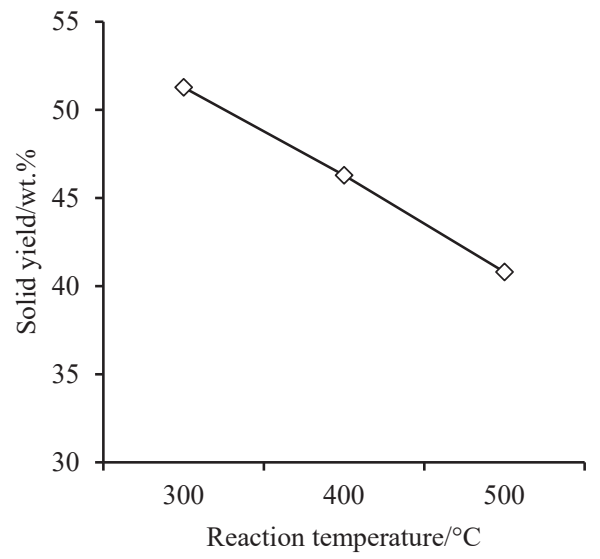

(a)

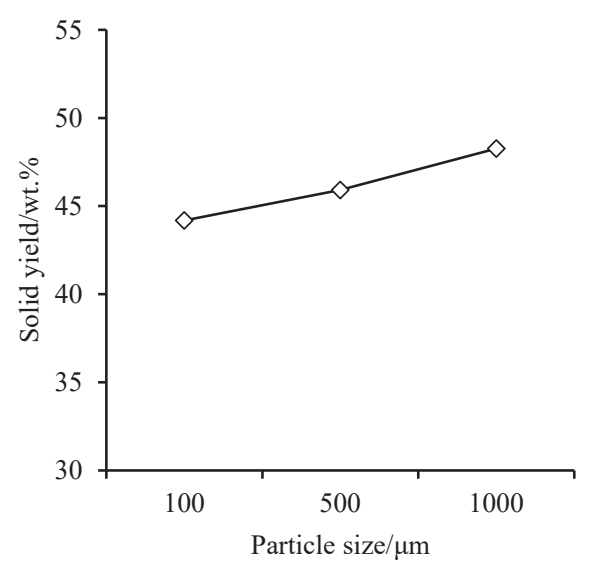

(b)

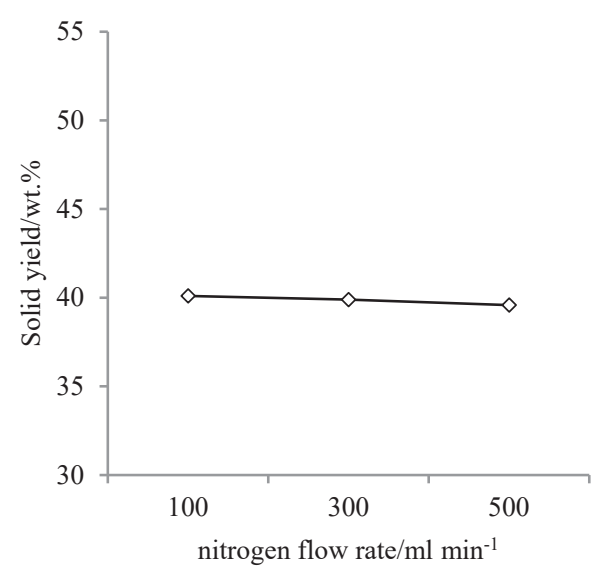

(c)

Fig. 3. Main effect plot for test parameters on pyrolysis solid yield based on data means.

\subsection{Optimization of solid yield from bamboo pyrolysis}

Table 6 shows the predicted solid yield and $\mathrm{S} / \mathrm{N}$ ratio at different factor combinations. The largest $\mathrm{S} / \mathrm{N}$ ratio is observed from a factor combination of $300^{\circ} \mathrm{C}$ reaction temperature, $1000 \mu \mathrm{m}$ feedstock particle size and $300 \mathrm{ml}$ $\mathrm{min}^{-1}$ of nitrogen flow rate, where $53.48 \mathrm{wt} . \%$ of solid yield was predicted. Three confirmation runs were conducted to validate the prediction, and a solid yield range of 49.57 to 52.11 wt.\% was obtained with approximately 3 to $7 \%$ difference from the predicted value. Another optimization approach using Response Optimizer feature in Minitab 17 was attempted using a test scenario (maximum solid yield, minimum liquid \& gas yields), resulting to a factor combination of $300^{\circ} \mathrm{C}$ reaction temperature, $1000 \mu \mathrm{m}$ feedstock particle size and $100 \mathrm{ml} \mathrm{min}{ }^{-1}$ nitrogen flow rate. From two confirmation runs conducted, the average solid yield of $50.63 \mathrm{wt} . \%$ was obtained and compared against the predicted value of 53.44 wt.\% with an almost negligible difference.

Table 6. Solid yield based on experimental result and prediction by Taguchi's L9 Orthogonal Array. Values obtained from experiments are marked with '*'.

\begin{tabular}{|c|c|c|c|c|c|}
\hline No & $\begin{array}{c}\text { Factor } \\
\text { A }\end{array}$ & $\begin{array}{c}\text { Factor } \\
\text { B }\end{array}$ & $\begin{array}{c}\text { Factor } \\
\text { C }\end{array}$ & $\begin{array}{l}\text { Solid } \\
\text { yield/ } \\
\text { wt. } \%\end{array}$ & $\begin{array}{l}\text { S/N } \\
\text { Ratio }\end{array}$ \\
\hline $1^{*}$ & 300 & 100 & 100 & 49.34 & 33.86 \\
\hline 2 & 300 & 100 & 300 & 49.39 & 33.87 \\
\hline 3 & 300 & 100 & 500 & 49.42 & 33.88 \\
\hline 4 & 300 & 500 & 100 & 51.18 & 34.18 \\
\hline $5^{*}$ & 300 & 500 & 300 & 51.16 & 34.18 \\
\hline 6 & 300 & 500 & 500 & 51.24 & 34.19 \\
\hline 7 & 300 & 1000 & 100 & 53.44 & 34.56 \\
\hline 8 & 300 & 1000 & 300 & 53.48 & 34.56 \\
\hline $9^{*}$ & 300 & 1000 & 500 & 53.33 & 34.54 \\
\hline 10 & 400 & 100 & 100 & 44.12 & 32.89 \\
\hline $11^{*}$ & 400 & 100 & 300 & 43.95 & 32.86 \\
\hline 12 & 400 & 100 & 500 & 44.19 & 32.91 \\
\hline 13 & 400 & 500 & 100 & 45.94 & 33.24 \\
\hline 14 & 400 & 500 & 300 & 45.97 & 33.25 \\
\hline $15^{*}$ & 400 & 500 & 500 & 46.14 & 33.28 \\
\hline $16^{*}$ & 400 & 1000 & 100 & 48.77 & 33.76 \\
\hline 17 & 400 & 1000 & 300 & 48.24 & 33.67 \\
\hline 18 & 400 & 1000 & 500 & 48.27 & 33.67 \\
\hline 19 & 500 & 100 & 100 & 38.88 & 31.80 \\
\hline 20 & 500 & 100 & 300 & 38.92 & 31.80 \\
\hline $21^{*}$ & 500 & 100 & 500 & 39.27 & 31.88 \\
\hline $22^{*}$ & 500 & 500 & 100 & 40.44 & 32.14 \\
\hline 23 & 500 & 500 & 300 & 40.73 & 32.20 \\
\hline 24 & 500 & 500 & 500 & 40.76 & 32.21 \\
\hline 25 & 500 & 1000 & 100 & 42.97 & 32.66 \\
\hline $26^{*}$ & 500 & 1000 & 300 & 42.69 & 32.61 \\
\hline 27 & 500 & 1000 & 500 & 43.03 & 32.68 \\
\hline
\end{tabular}




\section{Conclusion}

The influence of reaction temperature, feedstock particle size and nitrogen flow rate towards the solid yield in slow pyrolysis of bamboo was investigated and studied. The experimental design was based on Taguchi's L9 Orthogonal Array method. Based on the signal-to-noise $(\mathrm{S} / \mathrm{N})$ ratio, reaction temperature and feedstock particle size have the highest influence on solid yield while nitrogen flow rate has no significant effect. The reaction temperature was found to be inversely proportional to solid yield while the particle size was found to be directly proportional to the solid yield.

The experimental results were used to predict the solid yield for the untested parameter combinations. The solid yield with the largest $\mathrm{S} / \mathrm{N}$ ratio was identified at a factor combination of $300^{\circ} \mathrm{C}$ reaction temperature, $1000 \mu \mathrm{m}$

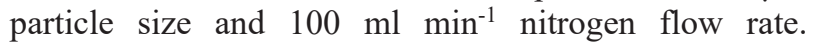
Confirmation runs produced a solid yield range of 49.57 to $52.11 \mathrm{wt} . \%$ in comparison to the predicted solid yield of 53.48 wt.\%. Another optimization approach with the aim to maximize solid yield and minimize liquid and gas yields produced a factor combination of $300^{\circ} \mathrm{C}$ reaction temperature, $1000 \mu \mathrm{m}$ particle size and $300 \mathrm{ml} \mathrm{min}^{-1}$ nitrogen flow rate. An average of solid yield of 50.63 wt. \% was obtained from confirmation runs against the predicted value of 53.44 wt. $\%$.

\section{Acknowledgement}

The authors would like to acknowledge the Ministry of Education Malaysia for awarding the Higher Institution of Centre of Excellence (HICoE) status to the Centre for Biofuel and Biochemical Research (Grant no. 015MA0-052).

\section{References}

[1] M. N. Uddin et al., "An Overview of Recent Developments in Biomass Pyrolysis Technologies," Energies, vol. 11, no. 11, 2018.

[2] J. A. Garcia-Nunez et al., "Historical Developments of Pyrolysis Reactors: A Review," Energy \& Fuels, vol. 31, no. 6, pp. 5751-5775, 2017.

[3] W. J. Liu, W. W. Li, H. Jiang, and H. Q. Yu, "Fates of Chemical Elements in Biomass during Its Pyrolysis," Chem Rev, vol. 117, no. 9, pp. 6367-6398, May 102017.

[4] V. Dhyani and T. Bhaskar, "A comprehensive review on the pyrolysis of lignocellulosic biomass," Renewable Energy, vol. 129, pp. 695716, 2018.

[5] S. Wang, G. Dai, H. Yang, and Z. Luo, "Lignocellulosic biomass pyrolysis mechanism: A state-of-the-art review," Progress in Energy and Combustion Science, vol. 62, pp. 33-86, 2017.

[6] K. Weber and P. Quicker, "Properties of biochar," Fuel, vol. 217, pp. 240-261, 2018.
F. R. Oliveira, A. K. Patel, D. P. Jaisi, S. Adhikari, H. Lu, and S. K. Khanal, "Environmental application of biochar: Current status and perspectives," Bioresour Technol, vol. 246, pp. 110-122, Dec 2017.

[8] Z. Tan, C. S. K. Lin, X. Ji, and T. J. Rainey, "Returning biochar to fields: A review," Applied Soil Ecology, vol. 116, pp. 1-11, 2017.

[9] J. S. Cha et al., "Production and utilization of biochar: A review," Journal of Industrial and Engineering Chemistry, vol. 40, pp. 1-15, 2016.

[10] J. Paz-Ferreiro, A. Nieto, A. Mendez, M. P. J. Askeland, and G. Gasco, "Biochar from Biosolids Pyrolysis: A Review," Int J Environ Res Public Health, vol. 15, no. 5, May 102018.

[11] P. Roy and G. Dias, "Prospects for pyrolysis technologies in the bioenergy sector: A review," Renewable and Sustainable Energy Reviews, vol. 77, pp. 59-69, 2017.

[12] H. Wang, X. Wang, Y. Cui, Z. Xue, and Y. Ba, "Slow pyrolysis polygeneration of bamboo (Phyllostachys pubescens): Product yield prediction and biochar formation mechanism," Bioresour Technol, vol. 263, pp. 444-449, Sep 2018.

[13] D. Chen, X. Yu, C. Song, X. Pang, J. Huang, and Y. Li, "Effect of pyrolysis temperature on the chemical oxidation stability of bamboo biochar," Bioresour Technol, vol. 218, pp. 1303-6, Oct 2016.

[14] L. F. Fialho et al., "Slow pyrolysis of bamboo: an approach on quality of charcoal and greenhouse gases emission," Revista Brasileira de Ciências Agrárias - Brazilian J Agric Sci, vol. 14, no. 4, pp. 1-6, 2019.

[15] D. Chen, J. Zhou, and Q. Zhang, "Effects of heating rate on slow pyrolysis behavior, kinetic parameters and products properties of moso bamboo," Bioresour Technol, vol. 169, pp. 313319, Oct 2014.

[16] J. Yu, L. Sun, C. Berrueco, B. Fidalgo, N. Paterson, and M. Millan, "Influence of temperature and particle size on structural characteristics of chars from Beechwood pyrolysis," J Anal App Pyrolysis, vol. 130, pp. 127-134, 2018.

[17] A. Demirbas, "Effects of temperature and particle size on bio-char yield from pyrolysis of agricultural residues," J Anal App Pyrolysis, vol. 72, no. 2, pp. 243-248, 2004.

[18] Y. H. Chan, K. V. Dang, S. Yusup, M. T. Lim, A. M. Zain, and Y. Uemura, "Studies on catalytic pyrolysis of empty fruit bunch (EFB) using Taguchi's L9 Orthogonal Array," Journal of the Energy Institute, vol. 87, no. 3, pp. 227234, 2014.

[19] L. Luo, C. Xu, Z. Chen, and S. Zhang, "Properties of biomass-derived biochars: Combined effects of operating conditions and biomass types," Bioresour Technol, vol. 192, pp. 83-9, Sep 2015. 